\title{
Comparative proteomics of related symbiotic mussel species reveals high variability of host-symbiont interactions
}

\author{
Ruby Ponnudurai ${ }^{1,2}$. Stefan E. Heiden $\mathbb{1}^{1} \cdot$ Lizbeth Sayavedra $\mathbb{1}^{3,4} \cdot$ Tjorven Hinzke $^{1,5} \cdot$ Manuel Kleiner $\mathbb{D}^{6}$. \\ Christian Hentschker $^{7} \cdot$ Horst Felbeck $^{8} \cdot$ Stefan M. Sievert $\mathbb{B}^{9} \cdot$ Rabea Schlüter $^{10} \cdot$ Dörte Becher $\mathbb{E}^{5,7}$. \\ Thomas Schweder $\mathbb{B}^{1,5} \cdot$ Stephanie Markert $\mathbb{D}^{1,5}$
}

Received: 12 April 2019 / Revised: 19 June 2019 / Accepted: 25 August 2019 / Published online: 4 November 2019

(c) The Author(s) 2019. This article is published with open access

\begin{abstract}
Deep-sea Bathymodiolus mussels and their chemoautotrophic symbionts are well-studied representatives of mutualistic host-microbe associations. However, how host-symbiont interactions vary on the molecular level between related host and symbiont species remains unclear. Therefore, we compared the host and symbiont metaproteomes of Pacific $B$. thermophilus, hosting a thiotrophic symbiont, and Atlantic B. azoricus, containing two symbionts, a thiotroph and a methanotroph. We identified common strategies of metabolic support between hosts and symbionts, such as the oxidation of sulfide by the host, which provides a thiosulfate reservoir for the thiotrophic symbionts, and a cycling mechanism that could supply the host with symbiont-derived amino acids. However, expression levels of these processes differed substantially between both symbioses. Backed up by genomic comparisons, our results furthermore revealed an exceptionally large repertoire of attachment-related proteins in the B. thermophilus symbiont. These findings imply that host-microbe interactions can be quite variable, even between closely related systems.
\end{abstract}

Supplementary information The online version of this article (https:// doi.org/10.1038/s41396-019-0517-6) contains supplementary material, which is available to authorized users.

Stephanie Markert

stephanie.markert@uni-greifswald.de

1 Institute of Pharmacy, University of Greifswald, Greifswald, Germany

2 European Molecular Biology Laboratory, Meyerhofstrasse 1, 69117 Heidelberg, Germany

3 Max Planck Institute for Marine Microbiology, Bremen, Germany

4 Quadram Institute of Bioscience, Norwich, UK

5 Institute of Marine Biotechnology, Greifswald, Germany

6 Department of Plant and Microbial Biology, North Carolina State University, Raleigh, NC, USA

7 Institute of Microbiology, University of Greifswald, Greifswald, Germany

8 Scripps Institution of Oceanography, La Jolla, CA, USA

9 Woods Hole Oceanographic Institution, Woods Hole, MA, USA

10 Imaging Center of the Department of Biology, University of Greifswald, Greifswald, Germany

\section{Introduction}

Bathymodiolus mussels harbor chemosynthetic bacterial symbionts in their gills and thrive in diverse marine habitats worldwide [1-3]. The intracellular symbionts fix dissolved inorganic carbon into organic compounds using the oxidation of reduced chemicals, such as methane, $\mathrm{H}_{2} \mathrm{~S}$, short-chain alkanes, or hydrogen, as energy source [4-7]. Bathymodiolus symbioses show a high degree of host-symbiont specificity, i.e., each host species harbors one (or several) distinct symbiont phylotype(s) [8]. B. thermophilus, for example, which colonizes hydrothermal vent fields on the East Pacific Rise (EPR), hosts a thiotrophic (sulfur-oxidizing, SOX) symbiont [9, 10]. In contrast, B. azoricus from the Mid-Atlantic Ridge (MAR) contains two symbiont phylotypes, a SOX symbiont (thiotroph) and a methane-oxidizing (MOX) symbiont (methanotroph) [5]. Despite these differences, B. thermophilus and $B$. azoricus are phylogenetically closely related $[1,2]$, and their thiotrophic symbionts, too, show close phylogenetic proximity $[11,12]$.

Recently, we reported a number of physiological interactions between host and symbionts in B. azoricus that provide metabolic integrity to the symbiosis as a whole 
[13]. However, little is known about these interactions in other Bathymodiolus host-symbiont combinations. Our current study therefore aims to identify similarities and specific differences in metabolic and physical interactions in the two geographically distant Bathymodiolus species $B$. thermophilus and B. azoricus.

\section{Methods}

All methods are described in detail in the Supplementary Material. Briefly, for proteomic analyses, three B. thermophilus individuals were collected from the Tica vent field on the EPR at $9^{\circ} 50.39^{\prime} \mathrm{N}, 104^{\circ} 17.49^{\prime} \mathrm{W}$ in $2511 \mathrm{~m}$ water depth, and three B. azoricus specimens were collected from the Menez Gwen vent field on the MAR at $37^{\circ} 50^{\prime} 41^{\prime \prime} \mathrm{N}, 31^{\circ} 31^{\prime}$ $10^{\prime \prime} \mathrm{W}$ in $860 \mathrm{~m}$ water depth. The bivalves were dissected on board, and gills and foot tissue samples were separately frozen immediately. In addition, symbiont and host fractions were enriched from gill homogenate by differential centrifugation and/or gradient centrifugation [14] and enrichment was confirmed by CARD-FISH analyses. The soluble proteome was extracted from all sample types. To enhance identification of symbiont membrane proteins, which could be involved in host interactions, we additionally extracted the membrane proteome of gill samples (both hosts) and enriched symbiont samples (B. azoricus). Supplementary Table S1a shows an overview of all sample types and replicate numbers analyzed in this study. Mass spectrometric analyses were performed using an LTQOrbitrap Velos mass spectrometer and/or an LTQ-Orbitrap Classic mass spectrometer (both Thermo Fisher, Bremen, Germany). MS/MS spectra were searched against an inhouse compiled comprehensive target-decoy database containing protein sequences of Bathymodiolus symbionts and host. Normalized spectral abundance factors were calculated as a measure of relative protein abundance in each sample (\%NSAF) and for each organism (\%OrgNSAF). Significant abundance differences between (a) thiotrophic symbiont protein orthologs in $B$. thermophilus and $B$. azoricus, and (b) different $B$. thermophilus sample types were determined using a Welch's $t$-test with permutationbased false discovery rate of $5 \%$. To support our proteomic observations, we conducted comparative genome analyses, which included four thiotrophic Bathymodiolus symbionts (of B. thermophilus, B. azoricus, B. septemdierum, and Bathymodiolus. sp.), two thiotrophic clam symbionts ("Candidatus Ruthia magnifica" and "Candidatus Vesicomyosocius okutanii") and two free-living SOX bacteria ("Candidatus Thioglobus autotrophicus" and "Candidatus Thioglobus singularis"), whose genomes were obtained from GenBank and IMG (Supplementary Table S1b). The protein sequence database and all proteome raw data are available via PRIDE [15] with the dataset identifier PXD011639.

\section{Results and discussion}

Our metaproteome analysis of two Bathymodiolus symbioses provided a detailed picture of individual metabolic processes and hitherto unknown interactions between all symbiotic partners (Fig. 1). The most prominent similarities and differences observed between $B$. azoricus and $B$. thermophilus are outlined below (for an overview of total protein identifications in all sample types see Supplementary Results I).

(1) Total symbiont biomass was substantially higher in B. thermophilus than in B. azoricus (Fig. 2). While the SOX symbiont population of $B$. thermophilus contributed $60 \%$ of total gill biomass, the total symbiont population of $B$. azoricus contributed only $25.3 \%$ (SOX: $16.4 \%$, MOX: $8.9 \%$, calculated based on protein abundance [16], Supplementary Table S8). This suggests that B. thermophilus may acquire a higher proportion of its nutrition through its symbionts than $B$. azoricus, in which filter-feeding might play a more prominent role. Previous findings based on the degree of convolution in the digestive tract in both mussels [17] and on the incorporation of dissolved and particulate organic matter in B. azoricus [18] support this idea. B. thermophilus specimens in our study were sampled in notably greater water depth $(2511 \mathrm{~m})$ and thus probably had access to less sinking biomass for filter-feeding than $B$. azoricus specimens (860 $\mathrm{m}$ depth). As thiotrophic and methanotrophic symbionts supposedly contribute equally to B. azoricus' nutrition (as suggested for Bathymodiolus sp. [19]), the presence of the methanotroph likely does not counterbalance the lower total symbiont biomass, indicating that $B$. azoricus may indeed receive less nutrients from its symbiont population than $B$. thermophilus. The relative contributions of symbiont-derived nutrition and filterfeeding in B. azoricus appear to vary with season and physiological host factors such as mussel size [20-22]. We can therefore not rule out that dissimilar specimen sizes and sampling dates for B. thermophilus and B. azoricus (see Supplementary Methods) may have influenced our results, but we assume that this potential effect is negligible.

(2) Both Bathymodiolus hosts appear to oxidize sulfide and provide a thiosulfate reservoir for their symbionts. We identified a host sulfide:quinone reductase (Sqr) homolog (BAGiLS_015482,61\% sequence identity to mitochondrial sulfide:quinone oxidoreductase of the copepod Eurytemora affinis) in B. thermophilus, and a host sulfurtransferase (BAGiLS_000284, 53.8\% identity to sulfurtransferase of the Pacific oyster Crassostrea gigas) in B. thermophilus and B. azoricus (Fig. 1, Supplementary Tables S2 and S3). Both 


\section{Bathymodiolus thermophilus}

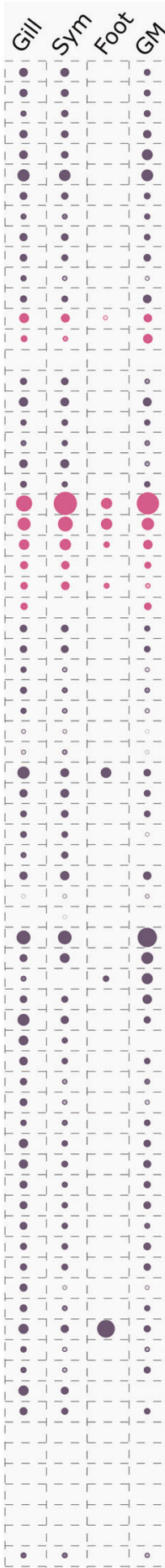

Bathymodiolus azoricus

Dissimilatory sulfite reductase DsrA Dissimilatory sulfite reductase DsrB ATP sulfurylase Sa

Adenylylsulfate reductase AprB Adenylylsulfate reductase AprM Adenylylsulfate reductase AprA Thiosulfate oxidation protein SoxY Thiosulfate oxidation protein SoxY Thiosulfate oxidation protein Sox Thiosulfate oxidation protein SoxA Thiosulfate oxidation protein SoxX Rhodanese-like protein Rhd 1 Thiosulfate sulfurtransferase Ts Sulfide:quinone reductase Sq Uptake hydrogenase Hup Transketolase TktA

RubisCO large subunit Cbbl Phosphoglycerate kinase Pgk Oxaloacetate decarboxylase OadA Glyceraldehyde-3-phosphate dehydrogenase GapA Succinate dehydrogenase, flavoprotein Sdh Lactate/Malate dehydrogenase Mdh Phosphoenolpyruvate carboxykinase PckA

Pyruvate carboxyltransferase PycA Oxoglutarate dehydrogenase Odh Carbonic anhydrase CA Glutamine synthetase GInA Glutamate synthase GItD

Nitrogen regulatory protein P-II GInK

Nitrate reductase subunit alpha NarG

Nitrate reductase subunit beta NarH Nitrate reductase catalytic subunit NapA Nitrite reductase large subunit NirB DNA-binding protein HU HupB

Ketol-acid reductoisomerase IlvC Aspartate aminotransferase AatA/AspC Tetrahydropicolinate $\mathrm{N}$-succinyltransferase DapD Amino acid transporter protein AapJ/GIt Amino acid transporter permease AapQ/GIt Amino acid transporter permease AapM/GItK Outer membrane porin Omp1/Po Outer membrane porin Omp2/Po Toxin TcaC hypothetical protein $\mathrm{BGC} 33$ T 01095 hypothetical protein BGC33-02135 hypothetical protein BGC33_02135 hypothetical protein BGC33_07690 hypothetical protein BGC33-0233 hypothetical protein BGC33-07755

hypothetical protein BGC33-13065

hypothetical protein BGC33-03760

hypothetical protein BGC33-03390

hypothetical protein BGC33-13060

hypothetical protein BGC33_07695

hypothetical protein BGC33-15000

hypothetical protein BGC33-02790

hypothetical protein BGC33-13370

hypothetical protein BGC33-09725

hypothetical protein BGC33-15265

hypothetical protein BGC33_08245

hypothetical protein BGC33-1528

hypothetical protein BGC33-01000

hypothetical protein BGC33-15285

Cadherin domain-containing protein Cadherin domain-containing protein Cadherin-like protein coagulation factor 5/8 type Plasmid $28.1 \mathrm{kDa}$ protein Insecticidal toxin complex protein Type I-F CRISPR protein Y1726/Csy 3
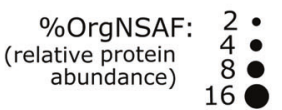

Bth Thiotroph

Bth Host
जी 5ा

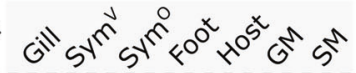

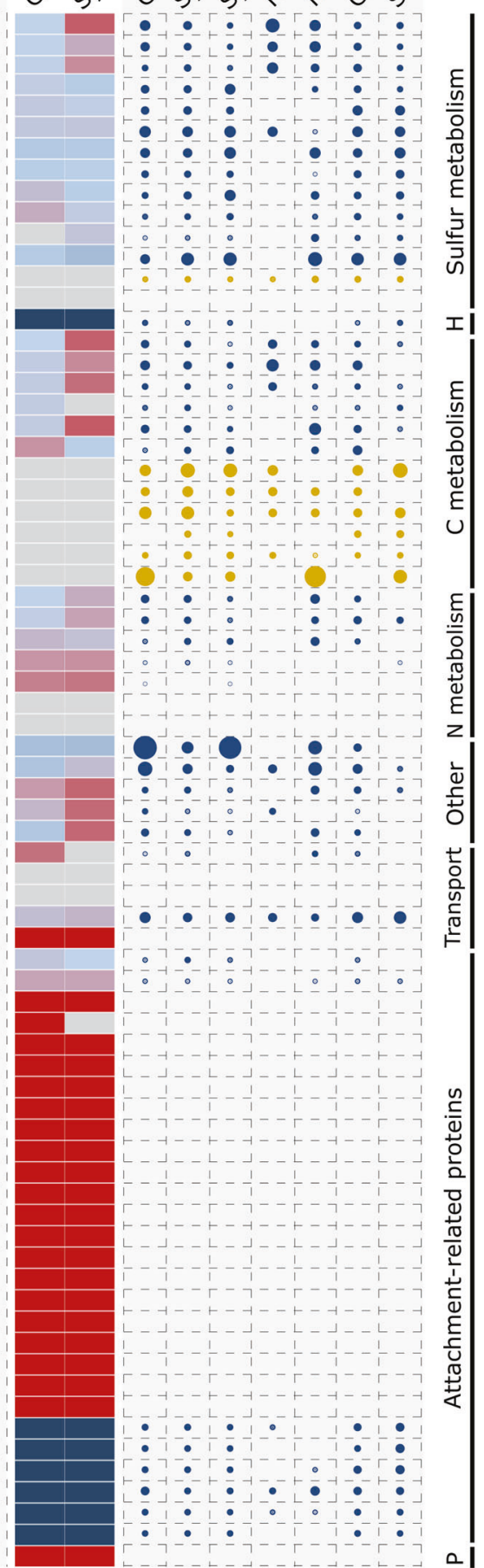

Baz Thiotroph

Baz Host

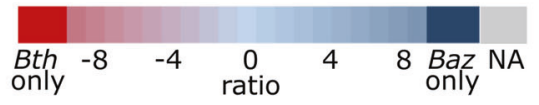

are involved in the mitochondrial oxidation of sulfide to thiosulfate (Fig. 3a). They were enriched or exclusively detected in symbiont-containing samples compared with symbiont-free foot samples, indicating that mitochondrial sulfide oxidation is particularly relevant near the symbionts. As an inhibitor of aerobic respiration, hydrogen sulfide is 
Fig. 1 Relative abundance of proteins in major metabolic categories in B. thermophilus (Bth) and B. azoricus (Baz). Bubble size corresponds to protein abundance in \%OrgNSAF (average values, for replicate numbers see Supplementary Table S1a; see Supplementary Tables S2 and S3 for a complete list of all identified proteins). Sample types: we analyzed the soluble proteome of symbiont-containing whole gill tissue (Gill) and symbiont-free foot tissue (Foot). In addition, we selectively enriched symbiont fractions (symbiont cell pellet, Sym) and host proteins (host-enriched supernatant, Host, $\mathrm{Baz}$ only) from gill tissue using gradient centrifugation, and analyzed their soluble proteome. For enhanced identification of membrane-associated symbiont proteins, we additionally analyzed the membrane proteome of whole gill tissue samples (gill membrane fraction, GM) and enriched symbionts (symbiont membrane fraction, SM, Baz only). Baz Sym samples were analyzed in an LTQ-Orbitrap Velos (V) mass spectrometer and in an LTQ-Orbitrap Classic (O) mass spectrometer. The heat map in the center shows ratios of symbiont protein abundance in $B$. thermophilus and B. azoricus Gill and Sym samples (Velos measurements only). Ratios were calculated from CLR-transformed \%OrgNSAF values (see Supplementary Methods). Negative ratios (red cells) indicate higher abundance in $B$. thermophilus, while positive ratios (blue cells) indicate higher abundance in B. azoricus. Gray cells (NA) indicate proteins that were either not compared, or that lacked the minimum number of valid values for reliable ratio calculations (see also Supplementary Table S4). Major metabolic categories are indicated on the right. $\mathrm{H}$ hydrogen oxidation, $\mathrm{P}$ phage defense



Fig. 2 Biomass contributions of symbionts in B. thermophilus and $B$. azoricus. Total symbiont biomass was substantially higher in $B$. thermophilus than in B. azoricus in whole gill tissue as well as in enriched symbiont fractions and in gill membrane fractions. Biomass contributions were calculated from the total number of spectra recorded for each organism during MS/MS analyses [16]. Error bars indicate standard deviations (all $B$. thermophilus samples: $n=3 ; B$. azoricus enriched symbiont fraction and whole gill tissue: $n=2 ; B$. azoricus gill membrane fraction: two biological replicates were pooled for MS analysis). SOX sulfur-oxidizing symbiont, MOX methaneoxidizing symbiont

toxic to aerobic organisms [23]. Invertebrate hosts of thiotrophic bacteria have therefore developed various strategies to shield their tissues from sulfide toxicity [24, 25], including the oxidation of sulfide into less harmful sulfur forms [26]. Our results strongly support the idea that $B$. thermophilus turns toxic sulfide into the less toxic thiosulfate by mitochondrial sufide oxidation, which may effectively function as a means of sulfide detoxification. This concept was first described for the thiotrophic symbiont-hosting clam Solemya reidi [27], but has since been reported for various other symbiotic and nonsymbiotic animals, including Bathymodiolus species [28-30].

The thiotrophic symbionts of $B$. thermophilus and $B$. azoricus use thiosulfate as an energy source [13, 31]. Proteins required for this thiosulfate oxidation process, i.e., the Sox multienzyme complex, showed quite similar total abundances in both thiotrophic symbionts in this study, with $2.03 \%$ OrgNSAF in gill tissue in B. azoricus and $1.98 \%$ in B. thermophilus (Fig. 1, Supplementary Tables S2-S4). This suggests that both symbionts experience comparable thiosulfate levels in their microhabitat, the gill tissue, although their macro-environments differ with respect to host species and geographic location. As previously suggested [31, 32], mitochondrial sulfide oxidation in Bathymodiolus gills may thus create a pool of thiosulfate, which provides a stable energy source for the thiotrophic symbionts.

(3) We identified several copies of the host enzyme carbonic anhydrase (CA) with significantly higher abundances in symbiont-containing samples than in foot tissue samples in both Bathymodiolus hosts, indicating the involvement of these enzymes in symbiosis-related processes (Fig. 1, Supplementary Fig. S2). CAs interconvert $\mathrm{HCO}_{3}{ }^{-}$ and $\mathrm{CO}_{2}$, turning the diffusible gas $\mathrm{CO}_{2}$ into a nondiffusible form (and back). The two CA homologs BAGiLS_000922 and BAGiLS_000924 were the most abundant proteins in $B$. azoricus gill samples (5.2\%OrgNSAF) and host-enriched gill supernatant samples (6.9 \%OrgNSAF; Supplementary Table S3, Fig. 1). In contrast, while three CAs were detected in B. thermophilus symbiont-containing samples (BAGiLS_000922, BAGiLS_000924. BAGiLS_003177), their total abundance was about 100 -fold lower $(0.052 \%$ OrgNSAF in gills, $0.066 \%$ OrgNSAF in enriched symbiont samples, Supplementary Table S2) than in B. azoricus. We hypothesize that the high expression of host $\mathrm{CA}$ in $B$. azoricus may be a response to $\mathrm{CO}_{2}$ released by the methanotrophic symbiont as end-product of methane oxidation. Possibly, $\mathrm{CA}$ in gill tissue may convert this methanotroph-derived $\mathrm{CO}_{2}$ to $\mathrm{HCO}_{3}^{-}$, thus immobilizing and concentrating it for efficient fixation by the thiotroph. A function of abundant host CA in providing chemoautotrophic symbionts with inorganic carbon has been suggested for several marine invertebrates, including various Bathymodiolus species, Calyptogena species, and Riftia pachyptila [33-35]. In $B$. thermophilus, which lacks a methanotrophic symbiont, $\mathrm{CO}_{2}$ concentrations might be lower, which would require lower $\mathrm{CA}$ abundance, compared with $B$. azoricus. Both hosts thus appear to regulate 

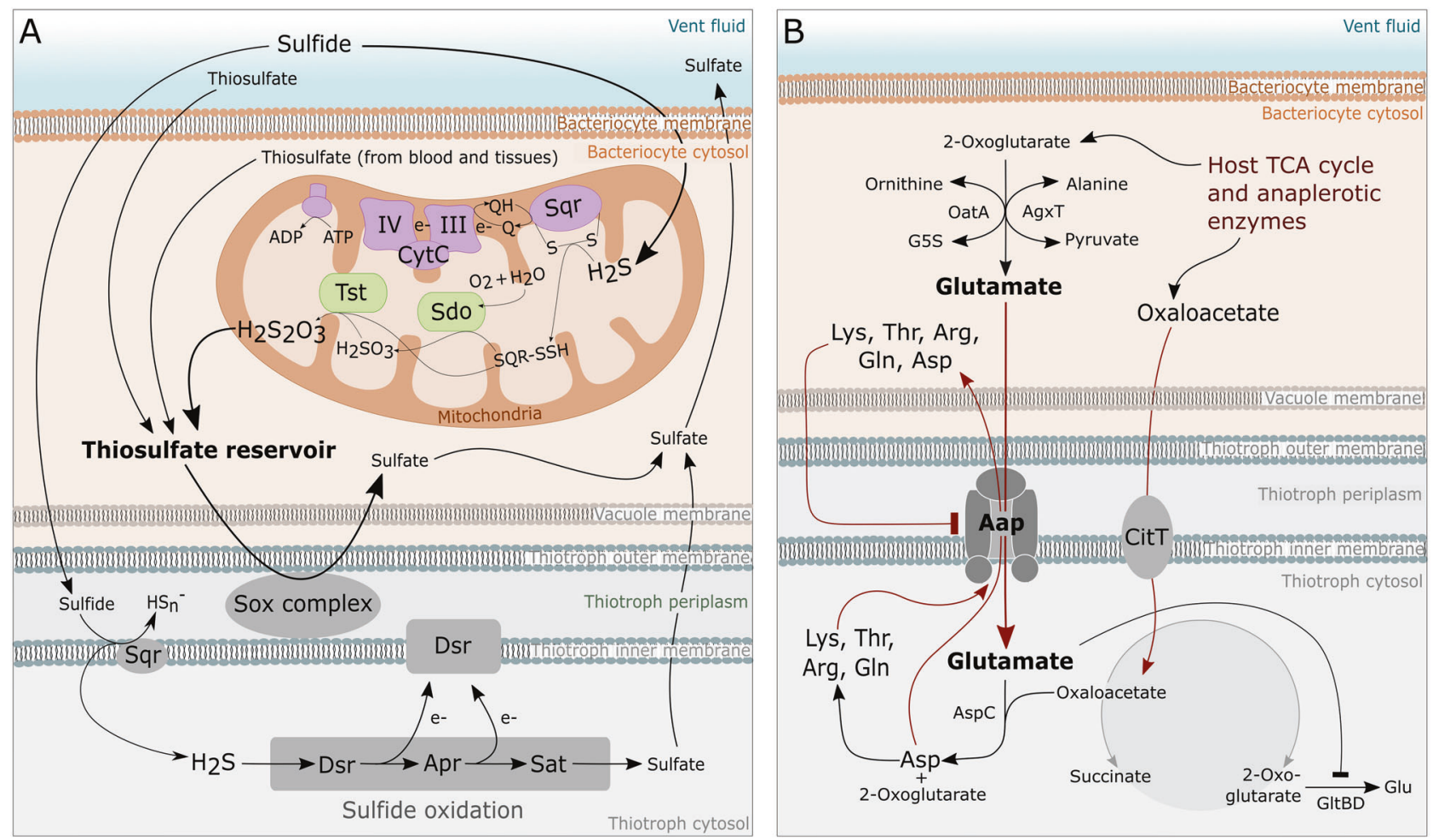

Fig. 3 Metabolic interactions in Bathymodiolus mussels. a Thiosulfate generated by mitochondrial sulfide oxidation may accumulate in host tissues and could be used as an energy source by the thiotrophic symbiont. Purple: host mitochondrial membrane-associated enzymes. Green: host mitochondrial matrix enzymes. Gray: thiotrophic symbiont enzymes. Tst thiosulfate sulfurtransferase, Sdo sulfur dioxygenase, Sqr sulfide:quinone reductase, III coenzyme Q complex of respiratory chain, IV cytochrome c oxidase complex, Dsr dissimilatory sulfite reductase complex, Apr adenylylsulfate reductase complex, Sat ATP sulfurylase. Please note that sulfate and thiosulfate transport across host and symbiont membranes involves transporter proteins, which are not shown in this figure, because their identities and exact functions are yet unclear. b Proposed model of amino acid cycling between host

their enzyme repertoire according to the specific requirements of their respective symbionts (Supplementary Discussion II, Supplementary Fig. S2).

(4) An amino acid cycling mechanism could provide Bathymodiolus hosts with symbiont-derived amino acids and appears to be particularly relevant in B. thermophilus. We detected a broad specificity L-amino acid ABC transporter (AapJQMP) in both Bathymodiolus SOX symbiont proteomes, which could be involved in selective "leakage" of symbiont amino acids to the host (Fig. 3b). Aap has a preference for polar amino acids and acts not only as an uptake transporter, but-in the presence of extracellular amino acids-also as an efflux transporter [36, 37]. In the well-studied Rhizobium symbiosis, Aap was shown to enable the cycling of amino acids between the plant host and root bacteroids [38, 39]. The glutamategenerating host enzymes ornithine aminotransferase (OatA: BAGiLS_006873, BAGiLS_004723) and alanine and thiotrophic symbionts in Bathymodiolus. The symbiont's general L-amino acid ABC transporter Aap imports host glutamate and exports aspartate (and presumably other amino acids) synthesized by the symbiont. Red arrows indicate amino acid biosynthetic routes that are shared between host and symbiont, whereas black indicates routes that are exclusive to the host or the symbiont. Arrows with flat ends suggest an inhibitory action. OatA: host ornithine aminotransferase, AgxT: host alanine aminotransferase, AspC: symbiont aspartate transaminase, GltBD: symbiont glutamate synthase, CitT: symbiont citrate transporter, Dct: symbiont tripartite ATP-independent periplasmic transporter. Lys, Thr, Arg, Gln, Asp: lysin, threonine, arginine, glutamine, aspartate; G5S: L-glutamate 5-semialdehyde

aminotransferase (AgxT: BAGiLS_022026) were notably more abundant or even exclusively detected in symbiontcontaining samples compared with foot tissue in both Bathymodiolus hosts (Supplementary Tables S2 and S3). All identified peptides were unique to the host proteins and were not shared with any symbiont proteins. These proteins could produce glutamate in the direct vicinity of the symbionts for uptake by the bacterial Aap transporter. After import through Aap, glutamate could be transaminated in the bacterial cytoplasm by the symbiont's aspartate aminotransferase (AspC: OIR24744.1, SEH69114.1), which we identified in both thiotrophic symbionts, and the resulting aspartate could be recycled into the Bathymodiolus bacteriocyte. A similar amino acid cycling strategy was described in the Buchnera-aphid symbiosis [40]. Other amino acids besides aspartate and glutamate might also be cycled, as proposed for Rhizobium [38]. This mechanism would allow the Bathymodiolus host to 
compensate for its previously proposed inability to synthesize aspartate and many other amino acids autonomously ([13], Supplementary Table S5) by harnessing the symbiont's biosynthetic machinery (see also Supplementary Discussion III). Simultaneously, both B. azoricus and $B$. thermophilus seem to supply their respective thiotrophic symbionts with oxaloacetate, an essential intermediate the bacteria cannot synthesize on their own ([13], this study; Fig. 3b). Close metabolic interdependency thus seems to be a typical feature of Bathymodiolus symbioses.

Interestingly, Aap was considerably more abundant in the $B$. thermophilus symbiont (the periplasmic solutebinding subunit AapJ, OIR25769.1, alone contributed $\sim 1 \%$ of the entire symbiont proteome, Fig. 1), than in the $B$. azoricus thiotroph (SEH78249.1, <0.1\%OrgNSAF in the symbiont fraction). Possibly, this may be because $B$. thermophilus obtains a relatively larger part of its nutrition from its symbionts than $B$. azoricus (see above).

(5) Symbiont attachment-related proteins (ARPs) were highly abundant in $B$. thermophilus and may be involved in interactions with the host. We detected a large set of $129 B$. thermophilus symbiont proteins involved in surface-binding and cell-cell adhesion, which together made up $23.9 \%$ of the symbiont's proteome in gill tissue (Supplementary Table S6b). Most of these proteins (126) are predicted to be either attached to the symbiont cell surface or secreted into the surrounding host vacuole, and 127 were more abundant in gill samples (gill and/or gill membrane) than in symbiontenriched fractions. The B. azoricus thiotroph, on the other hand, expressed only 16 ARPs, accounting for $3.5 \%$ OrgNSAF in gill samples (Supplementary Table S6c). To judge whether the high number of ARPs observed in the $B$. thermophilus thiotroph poses an exception or rather a common feature of thiotrophic Bathymodiolus symbionts, we compared the $B$. thermophilus symbiont's genome to the genomes of three other thiotrophic Bathymodiolus symbionts, two thiotrophic clam symbionts, and two free-living thiotrophs. This screening showed that ARP-encoding genes are comparatively rare in the related bacteria, but occur in exceptionally high numbers in the $B$. thermophilus symbiont (see Supplementary Discussion IV, Supplementary Table S6a, Supplementary Figs. S1 and S5). While the exact function of ARPs in Bathymodiolus thiotrophs is unknown, several possible scenarios are conceivable (see Supplementary Discussion V for details): (a) ARPs might be involved in symbiont colonization of host tissue, because most of them were adhesins, invasins, cadherins, integrins, intimins, and other proteins known to play crucial roles in pathogenic bacteria during host colonization and persistence [41-44]. (b) Their extraordinarily high abundance in $B$. thermophilus may additionally suggest a role in attachment of symbiont cells to each other, i.e., the formation of a biofilm-like structure, or some kind of extracellular proteinaceous matrix around the symbiont cells. This matrix could, for example, serve as proteinaceous substrate that is leaked from the symbionts to the host. As B. thermophilus presumably relies relatively more on its symbiont for nutrition than B. azoricus (see above), higher abundances of leaked symbiont proteins (e.g., ARPs) might be required. (c) Several of the symbiont ARPs contained domains known to bind and interact with phages (e.g., Ig-like, fibronectin Type 3, immunoglobulin superfamily and Ctype lectins $[45,46])$, which may indicate that the proposed ARP matrix could protect the symbionts from phages (Supplementary Fig. S4, Supplementary Table S7). Moreover, as previously suggested for pathogens [47, 48], ARPs could enable the symbionts to interact with host phagocytes, potentially enabling them to circumvent host-induced apoptosis (Supplementary Fig. S3). Further in-depth studies will be required to verify these hypotheses.

\section{Conclusion}

Although B. thermophilus and B. azoricus holobionts are phylogenetically closely related, many of their host-symbiont interactions differ distinctly on the molecular level. Further studies are required to disentangle the respective influence of habitat conditions, biological host parameters (e.g., age, reproductive status), and of individual host-symbiont constellations. However, our results imply that a high degree of variability, even between closely related species, needs to be taken into account when studying host-microbe associations in model systems.

Acknowledgements Thanks to captain, crew, and pilots of the research vessels Atlantis (ROV Jason cruise AT26-10 in 2014) and Meteor (cruise M82-3 in 2010). We thank Jana Matulla, Sebastian Grund, and Annette Meuche for excellent technical assistance during sample preparation, MS measurements in the Orbitrap Classic, and TEM imaging preparation, respectively. We appreciate Nikolaus Leisch's help with TEM image interpretation, Inna Sokolova's advice on bivalve physiology, and Marie Zühlke's support during manuscript revision. RP was supported by the EU-funded Marie Curie Initial Training Network 'Symbiomics' (project no. 264774) and by a fellowship of the Institute of Marine Biotechnology e.V. TH was supported by the German Research Foundation DFG (grant MA 6346/2-1 to SM). The Atlantis cruise was funded by a grant of the US National Science Foundation's Dimensions of Biodiversity program to SMS (OCE-1136727).

Author contributions RP performed all practical methods, i.e., sampling, symbiont enrichments, CARD-FISH analyses, and sample preparation for MS; she also constructed the B. thermophilus database, analyzed the MS data, and drafted the manuscript. SEH performed genome comparisons, LS did phylogenetic analyses, and MK provided helpful advice during method development and data interpretation and helped with biomass calculations. CH and DB ran the MS measurements, HF was involved in sampling on-board the research vessel, SMS obtained funding for cruise AT26-10 and coordinated sampling as chief scientist. TH provided assistance with statistical analyses and 
took samples for electron microscopy, while RS performed transmission electron microscopy. TS and StM supervised the study. StM coordinated the experimental work and substantially revised the manuscript. All authors contributed to further manuscript revision.

\section{Compliance with ethical standards}

Conflict of interest The authors declare that they have no conflict of interest.

Publisher's note Springer Nature remains neutral with regard to jurisdictional claims in published maps and institutional affiliations.

Open Access This article is licensed under a Creative Commons Attribution 4.0 International License, which permits use, sharing, adaptation, distribution and reproduction in any medium or format, as long as you give appropriate credit to the original author(s) and the source, provide a link to the Creative Commons license, and indicate if changes were made. The images or other third party material in this article are included in the article's Creative Commons license, unless indicated otherwise in a credit line to the material. If material is not included in the article's Creative Commons license and your intended use is not permitted by statutory regulation or exceeds the permitted use, you will need to obtain permission directly from the copyright holder. To view a copy of this license, visit http://creativecommons. org/licenses/by/4.0/.

\section{References}

1. Miyazaki J, de Oliveira Martins L, Fujita Y, Matsumoto H, Fujiwara Y. Evolutionary process of deep-sea Bathymodiolus mussels. PLoS ONE. 2010;5:e10363. https://doi.org/10.1371/ journal.pone.0010363.

2. Lorion J, Duperron S, Gros O, Cruaud C, Samadi S. Several deepsea mussels and their associated symbionts are able to live both on wood and on whale falls. Proc Biol Sci. 2009;276:177-85.

3. Dubilier N, Bergin C, Lott C. Symbiotic diversity in marine animals: the art of harnessing chemosynthesis. Nat Rev Microbiol. 2008;6:725-40.

4. Distel DL, Lee HK, Cavanaugh CM. Intracellular coexistence of methano- and thioautotrophic bacteria in a hydrothermal vent mussel. Proc Natl Acad Sci USA. 1995;92:9598-602.

5. Duperron S, Bergin C, Zielinski F, Blazejak A, Pernthaler A, McKiness ZP, et al. A dual symbiosis shared by two mussel species, Bathymodiolus azoricus and Bathymodiolus puteoserpentis (Bivalvia: Mytilidae), from hydrothermal vents along the northern Mid-Atlantic Ridge. Environ Microbiol. 2006;8:1441-7.

6. Petersen JM, Zielinski FU, Pape T, Seifert R, Moraru C, Amann $\mathrm{R}$, et al. Hydrogen is an energy source for hydrothermal vent symbioses. Nature. 2011;476:176-80.

7. Rubin-Blum M, Paul Antony C, Borowski C, Sayavedra L, Pape $\mathrm{T}$, Sahling H, et al. Short-chain alkanes fuel mussel and sponge Cycloclasticus symbionts from deep-sea gas and oil seeps. Nat Microbiol. 2017;2:17093. https://doi.org/10.1038/nmicrobiol. 2017.93

8. Duperron S, Gaudron SM, Rodrigues CF, Cunha MR, Decker C, Olu K. An overview of chemosynthetic symbioses in bivalves from the North Atlantic and Mediterranean Sea. Biogeosciences. 2013;10:3241-67.

9. Kenk VC, Wilson BR. A new mussel (Bivalvia, Mytilidae) from hydrothermal vents in the Galapagos Rift-Zone. Malacologia. 1985;26:253-71.

10. Nelson DC, Hagen KD, Edwards DB. The gill symbiont of the hydrothermal vent mussel Bathymodiolus thermophilus is a psychrophilic, chemoautotrophic, sulfur bacterium. Mar Biol. 1995;121:487-95.

11. Roeselers G, Newton ILG. On the evolutionary ecology of symbioses between chemosynthetic bacteria and bivalves. Appl Microbiol Biotechnol. 2012;94:1-10.

12. Petersen JM, Wentrup C, Verna C, Knittel K, Dubilier N. Origins and evolutionary flexibility of chemosynthetic symbionts from deep-sea animals. Biol Bull. 2012;223:123-37.

13. Ponnudurai R, Kleiner M, Sayavedra L, Petersen JM, Moche M, Otto A, et al. Metabolic and physiological interdependencies in the Bathymodiolus azoricus symbiosis. ISME J. 2016;11:463-77.

14. Hinzke T, Kleiner M, Markert S, Centrifugation-based enrichment of bacterial cell populations for metaproteomic studies on bacteria-invertebrate symbioses. In: Becher D, editor. Microbial proteomics: methods and protocols. New York, NY: Springer New York; 2018. p. 319-34.

15. Vizcaíno, Juan A, Csordas A, del-Toro N, Dianes JA, Griss J, Lavidas I, et al. 2016 update of the PRIDE database and its related tools. Nucleic Acids Res. 2016;44:11033-11033.

16. Kleiner M, Thorson E, Sharp CE, Dong X, Liu D, Li C, et al. Assessing species biomass contributions in microbial communities via metaproteomics. Nat Commun. 2017;8:1558. https://doi. org/10.1038/s41467-017-01544-x.

17. Fiala-Médioni A, McKiness ZP, Dando P, Boulegue J, Mariotti A, Alayse-Danet AM, et al. Ultrastructural, biochemical, and immunological characterization of two populations of the mytilid mussel Bathymodiolus azoricus from the Mid-Atlantic Ridge: evidence for a dual symbiosis. Mar Biol. 2002;141:1035-43.

18. Riou V, Colaço A, Bouillon S, Khripounoff A, Dando P, Mangion $P$, et al. Mixotrophy in the deep sea: a dual endosymbiotic hydrothermal mytilid assimilates dissolved and particulate organic matter. Mar Ecol Prog Ser. 2010;405:187-201.

19. Pond DW, Bell MV, Dixon DR, Fallick AE, Segonzac M, Sargent JR. Stable-carbon-isotope composition of Fatty acids in hydrothermal vent mussels containing methanotrophic and thiotrophic bacterial endosymbionts. Appl Environ Microbiol. 1998;64:370-5.

20. Martins I, Colaço A, Dando PR, Martins I, Desbruyères D, Sarradin $\mathrm{P}-\mathrm{M}$, et al. Size-dependent variations on the nutritional pathway of Bathymodiolus azoricus demonstrated by a C-flux model. Ecol Model. 2008;217:59-71.

21. Riou V, Duperron S, Halary S, Dehairs F, Bouillon S, Martins I, et al. Variation in physiological indicators in Bathymodiolus azoricus (Bivalvia: Mytilidae) at the Menez Gwen Mid-Atlantic Ridge deep-sea hydrothermal vent site within a year. Mar Environ Res. 2010;70:264-71.

22. Dixon DR, Lowe DM, Miller PI, Villemin GR, Colaço A, SerrãoSantos R, et al. Evidence of seasonal reproduction in the Atlantic vent mussel Bathymodiolus azoricus, and an apparent link with the timing of photosynthetic primary production. J Mar Biol Assoc U K. 2006;86:1363-71.

23. Nicholls P, Marshall DC, Cooper CE, Wilson MT. Sulfide inhibition of and metabolism by cytochrome c oxidase. Biochem Soc Trans. 2013;41:1312-6.

24. Arp AJ, Childress JJ, Fisher CR. Metabolic and blood-gas transport characteristics of the hydrothermal vent bivalve Calyptogena magnifica. Physiol Zool. 1984;57:648-62.

25. Powell MA, Somero GN. Blood components prevent sulfide poisoning of respiration of the hydrothermal vent tube worm Riftia pachyptila. Science. 1983;219:297-9.

26. McMullin ER, Bergquist DC, Fisher CR. Metazoans in extreme environments: adaptations of hydrothermal vent and hydrocarbon seep fauna. Gravit Space Biol Bull. 2000;13:13-23.

27. Powell MA, Somero GN. Hydrogen sulfide oxidation is coupled to oxidative phosphorylation in mitochondria of Solemya reidi. Science. 1986;233:563-6. 
28. Beinart RA, Gartman A, Sanders JG, Luther GW, Girguis PR. The uptake and excretion of partially oxidized sulfur expands the repertoire of energy resources metabolized by hydrothermal vent symbioses. Proc Biol Sci. 2015;282:20142811. https://doi.org/10. 1098/rspb.2014.2811.

29. Grieshaber MK, Völkel S. Animal adaptations for tolerance and exploitantion of poisonous sulfide. Annu Rev Physiol. 1998;60:33-53.

30. Cavanaugh CM, McKiness ZP, Newton ILG, Stewart FJ. Marine chemosynthetic symbioses. In: Dworkin $\mathrm{M}$, et al., editors. The Prokaryotes: volume 1: symbiotic associations, biotechnology, applied microbiology. New York, NY: Springer New York; 2006. p. 475-507.

31. Fisher CR, Childress JJ, Oremland RS, Bidigare RR. The importance of methane and thiosulfate in the metabolism of the bacterial symbionts of two deep-sea mussels. Mar Biol. 1987;96:59-71.

32. Nelson DC, Fisher CR. Chemoautotrophic and methanotrophic endosymbiotic bacteria at deep-sea vents and seeps. In: Karl DM, editor. The microbiology of deep-sea hydrothermal vents. New York: CRC Press. 1995. p. 25-167.

33. Goffredi SK, Girguis PR, Childress JJ, Desaulniers NT. Physiological functioning of carbonic anhydrase in the hydrothermal vent tubeworm Riftia pachyptila. Biol Bull. 1999;196:257-64.

34. Hongo Y, Nakamura Y, Shimamura S, Takaki Y, Uematsu K, Toyofuku T, et al. Exclusive localization of carbonic anhydrase in bacteriocytes of the deep-sea clam Calyptogena okutanii with thioautotrophic symbiotic bacteria. J Exp Biol. 2013;216:4403-14.

35. Kochevar RE, Childress JJ. Carbonic anhydrase in deep-sea chemoautotrophic symbioses. Mar Biol. 1996;125:375-83.

36. Walshaw DL, Poole PS. The general L-amino acid permease of Rhizobium leguminosarum is an $\mathrm{ABC}$ uptake system that also influences efflux of solutes. Mol Microbiol. 1996;21:1239-52.

37. Hosie AH, Allaway D, Jones MA, Walshaw DL, Johnston AW, Poole PS. Solute-binding protein-dependent ABC transporters are responsible for solute efflux in addition to solute uptake. Mol Microbiol. 2001;40:1449-59.

38. Lodwig EM, Hosie AH, Bourdes A, Findlay K, Allaway D, Karunakaran R, et al. Amino-acid cycling drives nitrogen fixation in the legume-Rhizobium symbiosis. Nature. 2003;422:722-6.

39. Prell J, Poole P. Metabolic changes of rhizobia in legume nodules. Trends Microbiol. 2006;14:161-8.

40. Price DR, Feng H, Baker JD, Bavan S, Luetje CW, Wilson AC. Aphid amino acid transporter regulates glutamine supply to intracellular bacterial symbionts. Proc Natl Acad Sci USA. 2014;111:320-5.

41. Tsai JC, Yen MR, Castillo R, Leyton DL, Henderson IR, Saier MH Jr. The bacterial intimins and invasins: a large and novel family of secreted proteins. PLoS ONE. 2010;5:e14403. https:// doi.org/10.1371/journal.pone.0014403.

42. Dupuy AG, Caron E. Integrin-dependent phagocytosis - spreading from microadhesion to new concepts. J Cell Sci. 2008;121:1773-83.

43. Barlag B, Hensel M. The giant adhesin SiiE of Salmonella enterica. Molecules. 2015;20:1134-50.

44. Cao L, Yan X, Borysenko CW, Blair HC, Wu C, Yu L. CHDL: a cadherin-like domain in proteobacteria and cyanobacteria. FEMS Microbiol Lett. 2005;251:203-9.

45. Fraser JS, Yu Z, Maxwell KL, Davidson AR. Ig-like domains on bacteriophages: a tale of promiscuity and deceit. J Mol Biol. 2006;359:496-507.

46. Barr JJ, Auro R, Furlan M, Whiteson KL, Erb ML, Pogliano J, et al. Bacteriophage adhering to mucus provide a non-host-derived immunity. Proc Natl Acad Sci USA. 2013;110:10771-6.

47. Pizarro-Cerdá J, Cossart P. Bacterial adhesion and entry into host cells. Cell. 2006;124:715-27.

48. Baorto DM, Gao Z, Malaviya R, Dustin ML, van der Merwe A, Lublin DM, et al. Survival of FimH-expressing enterobacteria in macrophages relies on glycolipid traffic. Nature. 1997; 389:636-69. 